\title{
Nurses' drowsy driving prevention strategies: A qualitative exploratory multiple-case study
}

\author{
Gina Rhodes*, Joshua Bernstein, Ruth Grendell \\ University of Phoenix, United States
}

Received: October 25, 2018

Accepted: November 6, 2018

Online Published: March 11, 2019

DOI: $10.5430 /$ jnep.v9n6p73

URL: https://doi.org/10.5430/jnep.v9n6p73

\begin{abstract}
Objective: To explore the strategies registered and licensed practical nurses implemented to lessen the possibility of driving while drowsy after working nights in hospitals, nursing homes, and home health facilities. A review of literature indicated shift work, circadian rhythm interruptions and multiple stressors such as age, caring for children/aging parents and working multiple jobs may affect drowsy driving. Studies on global drowsy driving and cultural differences may affect international applicability. Further research was needed to better understand drowsy driving best practices, training modalities for health care workers, and developing a multidisciplinary collaboration between management and night-shift workers.

Methods: A qualitative, exploratory multiple-case method was utilized. Registered and licensed practical nurses $(\mathrm{N}=12)$ were interviewed.

Results: Identified themes including three major themes emerged from the data analysis. 1) Fatigue is a significant challenge that impedes driving home safely. 2) Night nurses experience significant additional stressors relating to caring for family, school, and multiple jobs. 3) Multiple strategies are helpful, but they do not replace the body's need for sleep. Strategies for managing drowsy driving and anxiety/stress producing issues were offered.

Conclusions: Twelve-night shift workers shared the challenges drowsy driving and anxiety/stress producing issues outside of the work-related duties. Health care administrators may use the results to gain insight for training nurses for the night shift to prevent drowsy driving injuries and fatalities. The results of the study may offer a platform for further investigation that may uncover best-practice strategies for health care administrators staffing other types of 24-hour medical care facilities.
\end{abstract}

Key Words: Nursing, Drowsy driving, Prevention

\section{INTRODUCTION}

Drowsy driving is a global problem,,$^{[1]}$ but few researchers have studied the strategies night-shift nurses implement to lessen the possibility of driving while drowsy. ${ }^{[2-6]}$ Associated influences on drowsy driving outside of work may include, age, caring for children/aging parents and working multiple jobs. Evidenced-based best practices for training new night shift nurses are needed. The objectives of this research were to explore the strategies registered and licensed practical nurses implemented to lessen the possibility of driving while drowsy after working nights in hospitals, nurs- ing homes, and home health facilities. Their strategies for managing night driving challenges and off-duty stressors such as caring for family, continuing education, and working multiple jobs were sought. The participants shared their experiences in telephone interviews and reported insights as to their unique ways of coping with drowsy driving and off duty stressor/anxieties.

\subsection{Background literature review}

Drowsiness impairs multitasking ability, reduces creativity, and reduces logical thinking while driving, which can lead to

*Correspondence: Gina Rhodes; Email: g5rhodes@email.phoenix.edu; Address: University of Phoenix, United States. 
accidents. ${ }^{[7]}$ Sleep deprivation can lead to tremors that affect the hands or legs of the driver, and the shaking may cause the loss of a firm grip on the steering wheel, leading to swerving from the designated lane. A drowsy driver may abruptly speed up or apply the brakes, leading to accidents. When driving, the brain may fall asleep while the sleep-deprived driver tries to stay awake, leading to lapses in attention. ${ }^{[7]}$

Monotonous driving conditions such as a commute to and from work can thus act as soporifics for a sleep-deprived driver. Empirical evidence shows that falling asleep is most likely to occur on long-distance driving trips in low-traffic or monotonous conditions. ${ }^{[8]}$ Sleep deprivation may lead to inattention to the road and obliviousness to potential hazards. ${ }^{[9]}$ Sleep-deprived drivers often have no conscious awareness of attention lapses or of being in a trance state. Their ability to respond to traffic stimuli is impaired while in this state. When joined with the dangers inherent in daily driving, sleep deprivation may lead to additional consequences for the driver and others who share the road. ${ }^{[8]}$

The night shift has been most challenging because of the inability of the body to adjust to the daytime hours of sleep. ${ }^{[2]}$ In this regard, researchers posited that night-shift nurses are more vulnerable to drowsy driving than their colleagues who work during the day. ${ }^{[2,3,5]}$ Several factors may contribute to sleep deprivation among nurses. For example, Scott et. al found that nurses who worked the night shift were at a higher risk of sleep deprivation because they did not typically get as much sleep between shifts as did nurses who worked morning or day shifts. ${ }^{[1]}$

Scott et al. also reported that among a sample of 30 nurses, 92 episodes of drowsing driving occurred, including five collisions or near collisions in just two weeks. ${ }^{[11]}$ Most of the participants in Scott et al.'s study reported poor sleep quality, severe sleepiness, and reduced alertness while driving. Researchers noted significant improvements in participants' sleep duration, quality, and readiness after the implementation of a program designed to reduce fatigue; however, daytime sleepiness did not decrease significantly. The strategies nurses implemented to minimize fatigue included daytime naps and breaks while working. ${ }^{[12]}$ Although these strategies helped to reduce fatigue and sleep deprivation, the researchers noted that nurses often expressed guilt when taking advantage of opportunities to catch up on rest.

\subsection{Literature review analysis}

The scope of studies relating to drowsy driving has focused on the causes of drowsy driving among nurses and its effect on the causation of accidents. Some studies have also focused on the management and prevention of drowsy driving and suggested remedial measures for this problem. ${ }^{[2,3,5]} \mathrm{Re}-$ searchers observed that men are more likely to report drowsy driving than women. Regarding demographics, incidences of drowsy driving decrease with age; older drivers had lower rates of drowsy driving. ${ }^{[12]}$ The observation regarding the reduction in drowsy driving among older drivers generally has not received further investigation because of the assumption that nurses experience this phenomenon because of their shift hours. ${ }^{[13]}$

Further research is necessary to investigate the variety of causes of drowsy driving. The high prevalence of drowsy driving among younger nurses implies that it is their lifestyle or lack of drowsy driving experience, and not just their work schedules that could lead to this phenomenon. ${ }^{[2]}$ Factors like staying up late for parties interfere with the sleep hours of the younger generation, and this could significantly increase drowsiness while driving. ${ }^{[14]}$ Older nurses, on the other hand, may be keener to work, and they may strictly adhere to the rest hours regardless of the time of day. Researchers have therefore not provided firm conclusions regarding the leading causes of drowsy driving among nurses.

Much of the existing scholarship relating to drowsy driving is quantitative. The quantitative nature of most drowsing driving research is likely because past researchers have been interested in quantifying incidences of drowsy driving, developing interventions to reduce occurrences of drowsy driving, and then empirically testing the effectiveness of those interventions. For example, Owens et al. described a large-scale study that involved the monitoring of over 3,500 drivers over several months in gathering data on drowsy driving as indicated by the eye movements of drivers. ${ }^{[15]}$

There is no shortage of research on drowsy driving. The boom in research on the topic in recent years indicates that this is a salient, timely, and unsolved problem. Most of the existing research is quantitative, focusing on empirically testing drowsy driving interventions, quantifying its incidence, and understanding relationships between drowsy driving and several risk factors. There is a shortage of qualitative research on the topic.

Analysis of drowsy driving uses insufficient information due to the nature of accidents that relate to this phenomenon. Data on crashes due to drowsy driving are unreliable because they depend upon police reports. The statistics are even harder to obtain when accidents result in fatalities, because such accidents may be due to a variety of factors. ${ }^{[16]}$ Nonetheless, researchers agree that drowsy drivers have inhibited judgment, and they are more likely to cause accidents on the road than other drivers. ${ }^{[16]}$ Data on the effect of drowsy driving also commonly emerges from interviews 
with nurses.

Nurses generally have fewer sleeping hours when they are working on a night shift than when they work during the day. ${ }^{[3]}$ Consequently, they are likely to suffer limited sleep patterns that may occasion drowsy driving. Nevertheless, some nurses fail to provide accurate information, as most of them feel that they are in control of their sleeping habits. ${ }^{[16]}$

\subsection{Gaps in the literature}

The literature covering drowsy driving among nurses covers several areas and provides a basis for the regulation of the working conditions of nurses. Nevertheless, coverage is minimal on the interventions that various health care providers have put in place to help workers on the night shift to sleep for the recommended number of hours. The literature has also not sufficiently addressed other factors in the lives of the nurses that cause drowsy driving. Such aspects as stress may impede nurses from maintaining sobriety while driving. Research on drowsy driving among nurses is inconsistent, and it leaves many questions unanswered about the multiple factors with associations with this phenomenon. Most of the literature on this topic is quantitative, which adds further support for the qualitative methodology for this study. Based on this review, there does not seem to be a great deal of tension in the literature on drowsy driving. Researchers seem to agree that it is a persistent problem, and there is an agreement regarding the influence of specific risk factors. ${ }^{[17,18]}$ The real tension in the literature is the lack of qualitative investigation necessary to provide an in-depth understanding of drowsy driving. Further, research is essential to understand drowsy driving among different populations of drivers better.

\subsection{Limitations of the existing literature}

Although there is an impressive body of research on drowsy driving, it focuses heavily on statistical investigations of predictors of drowsy driving or tests of the effectiveness of drowsy driving interventions. Further, most of the research fails to identify differences that may exist among different populations of drivers. Of interest is the dearth of scholarship on strategies employers and organizations implement to reduce drowsy driving among workers, as this would seem a significant, unaddressed organizational liability.

Whereas most scholars posited that drowsy driving among nurses relates to night-time sleeping, nurses are often having enough time for rest hours to manage night shifts. ${ }^{[19]}$ The sleep hours should provide nurses on the night shift time to rest so that they can be fresh for the next shift. ${ }^{[4]}$ Scholars have based their premises on the fact that the body is accustomed to working during the day, and night-time work interferes with sleeping patterns. Kunert et al. proposed that Published by Sciedu Press nurses are not the only workers who work during the night, but that cases of drowsy driving are not as prevalent among other professionals as among nurses. ${ }^{[20]}$ The conclusions of studies on nurses and drowsy driving have had limited scope, and as such, they are not generalizable as required in research.

\section{Methods}

Yin's qualitative tradition was most suitable approach for this study. ${ }^{[21]}$ A case design encouraged participants to share information to address the driving challenges of night-shift nurses and to promote further study to develop policies for educating nurses regarding driving strategies when drowsy. A college institution review board approval was granted prior to the beginning the study. Participants gave informed consent. Confidentiality was assured using pseudonyms. Data was securely stored. Identifying information including names and employment were not used.

\subsection{Sample and data collection}

A purposeful and snowball technique was used. The inclusion criteria for the present study were that all participants must be RNs or LPNs, currently working the night shift, and currently working in hospitals, nursing homes, or home health facilities. Other medical care facilities such as doctors' offices and medical clinics were excluded from the study under the assumption that these facility types do not staff for the night shift, and that participants would not share similar driving experiences with night-shift workers. Participants were not limited to one geographic region or health care system. Participants worked in a nursing home/assisted living/home health complex in Central Florida and several hospitals. Twelve participants demonstrated data saturation. Research questions consisted of demographic and open-ended questions (see Table 1). Open-ended questions helped participants discuss the topic. Data was collected by recorded individual interviews over the telephone. Although the interviews did not take place on the campus of any medical facility, permission was obtained to use contacts from gatekeepers, e.g. Central Florida nursing facilities, nursing associations, and social media outlets.

\subsection{Data analysis}

Interviews were sequentially reviewed, analyzed and compared in search of themes. Data collection and analysis occurred simultaneously. Audio tapes were transcribed by the first author. Transcripts were read while listening to the audio tapes for accuracy and to identify nuances. The transcripts were read line-by-line in a holistic approach. Highlighted statements and phrases were isolated and coded. ${ }^{[22]}$ Categories and themes were identified. As themes emerged, 
NVivo 12 software was used to generate theme files. Researchers field notes and memos were included in the analysis. Study participants were contacted as need for verification. Member validation with a small group of participants ensured the validity of interviews. Credibility was enhanced by referencing the existing literature to demonstrate the relationship between the results and the current research. To achieve quality, researchers biases and experiences were acknowledged with explicit descriptions and set aside. The researchers maintained a self-critical attitude about how personal assumptions might affect the research. A record of personal feelings biases, and insights was kept after each interview. ${ }^{[23]}$ Using software assistance for data analysis, such as NVivo 12, for coding textual narratives of interviews reduced the likelihood of mistakes such as missing keywords or phrases, and it enhanced the quality and credibility of the results. ${ }^{[24]}$ No unanticipated events impacted the data analysis procedures.

Table 1. Interview protocol

\begin{tabular}{l}
\hline Demographic Questions \\
\hline 1. Birth year: Sex: M/F \\
2. What is your current nursing position? \\
3. How many years have you been working as a nurse? \\
4. Do you have dependent children at home? (circle one): Y/N \\
5. If you have dependent children at home, how many? \\
6. If you have dependent children at home, are you a single parent? \\
Y/N \\
7. Are you a current student? Y/N \\
8. Are you currently working any other jobs? Y/N \\
If yes, how many hours do you work at this other job \\
per week, on average? \\
9. What is your one-way commute distance/time to your nursing \\
job? minutes miles \\
10. On average, approximately how many hours of sleep do you get \\
on a workday? \\
11. On average, approximately how many hours of sleep do you get \\
on a none workday
\end{tabular}

\section{Open-Ended Questions}

1. Tell me about your current position and how long you have worked as a nurse.

2. What shift do you work?

3. Do you work more than one job?

4. What is the distance from your work to your home?

5 . How many stops, if any, do you tend to make on your way home?

6. Describe how you generally feel prior to driving home from work.

7. Describe what challenges, if any, you face while driving home.

8. What strategies, if any, do you use to overcome those challenges when driving home?

9. Describe the amount of traffic you typically encounter during your commute home.

10. Have you ever discussed with your manager your experiences with sleepy/drowsy driving?

11. What do you feel nurse managers or organizational leaders could do to help nurses who struggle with sleepy/drowsy driving?

\section{Closure}

Is there anything else we have not talked about that you think I should know about sleepy/drowsy driving?

\section{RESUlTS}

\subsection{Demographic data}

Descriptive demographic data were collected (see Table 2). There were 11 females and one male, four registered nurses and eight licensed practical nurses.

\subsection{Themes}

An analysis of the 12 participants' responses revealed three core themes: (1) challenges of driving after the night shift, (2) strategies nurses used to remain alert, and (3) stressors and anxieties unique to night-shift workers. Table 3 sets out the research questions, related interview questions, and related themes. The themes are also described in detail below with participant quotes added to give a clear picture.

\subsubsection{Challenges driving after the night shift}

All 12 of the participants reported that fatigue or tiredness was the core obstacles they faced while driving home. All 12 participants discussed this topic, with 18 references in the interviews. Participants revealed two significant areas of driving challenges: (a) driving for more than 30 minutes, and (b) falling asleep at red lights. The nurses also shared that distance played a significant role in the complexities of night driving. One major driving challenge the nurses noted was driving for more than 30 minutes after working the night shift. Concerning the driving struggle, RNHOSP-1 stated, "I have struggled with falling asleep on the way to and from work." LPNNH-1 explained "I have a long commute, over 1 hour. I am good until the last half hour." LPNNH-2 shared:

$$
\text { I will always remember it ... it was a Saturday }
$$

ISSN 1925-4040 E-ISSN 1925-4059 
morning, no cars out and about, and I was half asleep driving - probably speeding. In the road I saw something, but I could not focus. I thought the shape was an animal ... it was a police officer trying to flag me down - to slow down... I got a ticket, but he probably saved my life.

Table 2. Summary of demographic data

\begin{tabular}{|c|c|c|}
\hline $\begin{array}{l}\text { Participants } \\
\mathrm{n}=12 \\
\text { Ages }=19-50 \\
\text { Gender } \mathrm{M}=1, \mathrm{~F}=11\end{array}$ & $\begin{array}{l}\text { Current Position } \\
\text { Registered Nurse }=4 \\
\text { Licensed Practical Nurse }=8\end{array}$ & $\begin{array}{l}\text { Cares for Dependent Child/Parent } \\
\text { Yes }=10 \\
\text { No }=1\end{array}$ \\
\hline $\begin{array}{l}\text { Employment Location } \\
\text { Hospital }=4 \\
\text { Home Health }=4 \\
\text { Nursing Home }=4\end{array}$ & $\begin{array}{l}\text { Current Position } \\
\text { Registered Nurse }=4 \\
\text { Licensed Practical Nurse }=8\end{array}$ & $\begin{array}{l}\text { Currently in school } \\
\text { Yes }=4 \\
\text { No }=8\end{array}$ \\
\hline $\begin{array}{l}\text { Years of Service } \\
1-5 \text { years }=4 \\
6-10 \text { years }=4 \\
11 \text { years or more }=4\end{array}$ & $\begin{array}{l}\text { Work more than one job } \\
\text { Yes }=5 \\
\text { No }=7\end{array}$ & $\begin{array}{l}\text { Hours of Sleep on Workday } \\
0-5 \text { hours }=7 \\
6-8 \text { hours }=4 \\
9 \text { hours or more }=1\end{array}$ \\
\hline $\begin{array}{l}\text { Marital Status } \\
\text { Married or Significant other }=3 \\
\text { Single }=4 \\
\text { Divorced }=3 \\
\text { Widow }=1\end{array}$ & $\begin{array}{l}\text { Distance (minutes) from work to home } \\
5-25=3 \\
30-45=7 \\
50-60 \text { or more }=2\end{array}$ & $\begin{array}{l}\text { Hours of Sleep on Non-Workday } \\
0-5 \text { hours }=7 \\
6-8 \text { hours }=3 \\
9 \text { or more }=2\end{array}$ \\
\hline
\end{tabular}

Table 3. Research questions, related interview questions, and related themes

\begin{tabular}{|c|c|c|}
\hline Research Question & Semi-Structured Question & Theme \\
\hline $\begin{array}{l}\text { RQ: What coping strategies do nurses } \\
\text { use to mitigate drowsy driving? }\end{array}$ & Q1. Describe how you generally feel prior to driving home from work. & Theme 1 \\
\hline $\begin{array}{l}\text { Sub RQ 1: } \\
\text { How do RNs and LPNs describe the } \\
\text { challenges they face while driving } \\
\text { home following night-shift work? }\end{array}$ & $\begin{array}{l}\text { Q2. How many stops, if any, do you tend to make on your way home? } \\
\text { Q3. What is the distance from your work to your home? } \\
\text { Q4. Describe the amount of traffic you typically encounter during your } \\
\text { commute home? } \\
\text { Q5. Describe what challenges, if any, you face while driving home? } \\
\text { Q 6. What strategies, if any, do you use to overcome those challenges when } \\
\text { driving home? } \\
\text { Q7. Have you ever fallen asleep behind the wheel? Please describe your } \\
\text { experience. }\end{array}$ & Theme 2 \\
\hline $\begin{array}{l}\text { Sub RQ 2: } \\
\text { How do RNs and LPNs identify the } \\
\text { stressors and anxiety that are unique } \\
\text { to shift work? }\end{array}$ & $\begin{array}{l}\text { Q1. Do you work more than one job? Describe how you manage multiple } \\
\text { employments. } \\
\text { Q2. Do you have dependent children/parents at home? Describe how you } \\
\text { manage their care. } \\
\text { Q3. Are you currently in school? Describe how you manage working nights } \\
\text { and going to school. }\end{array}$ & Theme 3 \\
\hline
\end{tabular}

Many (40\%) of the nurses interviewed struggled with stopping at red lights when driving after a night shift. RNHOSP-1 lamented, "I fell sound asleep at a stoplight one block away from the job. I suddenly woke up and got scared, because I didn't feel like I was going to doze off." RNHOSP-5 posited:

The issue with driving when you're tired [is]

that it sneaks up on you and before you know it, the tiredness has mixed your faculties enough, that you don't understand you are driving recklessly. I only have a three-mile trip home from work, but sometimes I don't remember stopping at the red lights or driving the last mile. 
LPNNH-3 reflected:

I could have avoided the accident.

I am so busy during the night at work that when I finally sit in my car, I just want to crash. When I drive home, my eyes are rolling, and I tend to fall asleep at a light. I once ran into someone (just a slight bump), although it was not totally my fault. I do feel that if I had been more alert,
Other challenges participants reported included experiencing a slower reaction time $(75 \%)$, difficulty gaging speed/distance from other vehicles $(66 \%)$, and visual challenges relating to low light or glare on the windshield (58\%).

Table 4. Participant responses to questions

\begin{tabular}{ll}
\hline Participant Response & Percentage of Responses \\
\hline Night Driving Challenges & $100 \%$ \\
Had fatigue and drowsiness prior to leaving work and during the drive home & $91 \%$ \\
Had slower reaction times & $75 \%$ \\
Had difficulties gaging vehicle speed and distance from other vehicles & $66 \%$ \\
Had visual challenges relating to low light or glare on windshield & $58 \%$ \\
Night Driving Strategies & $100 \%$ \\
Offered strategies to stay alert while driving & $91 \%$ \\
Ate a snack during the drive & $75 \%$ \\
Drank coffee on the drive & $41 \%$ \\
Stopped on the way home for a nap & $16 \%$ \\
Used an electronic alarm to warn when nodding off & \\
Stressors/Anxiety of Night Workers & $100 \%$ \\
Expressed stress/anxiety-producing issues & $58 \%$ \\
Cared for children under the age of 12 & $50 \%$ \\
Attended school full time or took courses & $41 \%$ \\
Worked on more than one job & $8 \%$ \\
Cared for aging parents over the age 65 & \\
\hline
\end{tabular}

\subsubsection{Family, education, and multiple job stressors}

All 12 participants expressed challenges with work/family/education and multiple job challenges (see Table 4). Nurses with dependent children or aging parents shared the struggle with time pressures, especially for individuals who have high family involvement or corresponding obligations.

\section{RNHOSP-4 said:}

I have two children. One is under the age 3-and a 6-month-old baby who I still breast feed. To save time, I compress milk in bottles so that my spouse can help feed when I am at work. After coming home from night-shift... I compress more milk and try to spend a few hours with the babies before going to sleep. I really don't get much sleep.

At the same time, nurses with aging parents voiced similar concerns. LPNHH-2 shared that her aged mother who lives with her has dementia. She lamented that "at this stage, mom has to be managed like a child.... The caretaker leaves after I get home.... I must remain alert to take her to adult day care ... then I can go to sleep."

Several nurses (41\%) explained that maintaining a second job was the only way to take care of financial commitments (see Table 4). RNHOSP-3 remarked that she had a business selling real estate during the day. She stated "I rarely get enough sleep during my off days. I spend most of the day showing clients homes. My plan is to one day work as a broker full time." LPNNH-4 works part time on the day shift at another medical facility. "Working both jobs is hard" she explained. "But, I got four kids to raise and I need the hours."

Continuing education is another challenge for night-shift nurses. Fifty percent (50\%) of the nurses shared that they are currently attending school after working the night shift (see Table 4). LPNHH-3 wants to finish school to become an RN. LPNHH-3 commented:

I work three 12-hour night shifts, and on some days after working the 11-7 shift, I drive from

ISSN 1925-4040 E-ISSN 1925-4059 
work straight to school for class or nursing clinicals. I am so tired most of the time, but one day I know the sacrifice of my time and sleep will pay off.

RNHOSP-4 wants to become a nurse practitioner. She works the night shift and takes most of her classes online. "The night-shift works well for me," she explained, "When things are slow at work, I try to read an article or two. When I get home, I [have] a nap then gets back to online class or on my writing assignments ... but it is hard." RNHOSP-1 stated that she had an associate degree, and that to maintain her current position, she must obtain a bachelor's degree.

\subsubsection{Strategies nurses used to stay awake}

All participants offered strategies they have implemented and recommend to others to remain awake when driving following a night shift. Most of the strategies related to actions before and during the drive home. Table 5 illustrates the most popular strategies and the percentages of participants utilizing the strategies. RNHOSP-2 explained, "I listen to loud music so that I can sing along at the top of my lungs." RNHOSP-4 noted that she often stops somewhere along the way home (usually a local restaurant) and takes a small nap there. However, she exclaimed that sleeping in a car is a poor substitute for real rested sleep in a bed.

Table 5. More drowsy driving strategies from participants

\begin{tabular}{ll}
\hline Participant Strategy & $\%$ \\
\hline Roll down the window & 93 \\
Eat lollipops, pretzels, or any hard candy & 86 \\
Drink lots of coffee or a sugar-filled snack & 86 \\
Listen to a riveting audio book & 80 \\
Listen to loud, stimulating music/sing aloud & 80 \\
Make sure to be rested before going to work & 80 \\
Stop at a fast-food restaurant and order a snack & 80 \\
Stop in a safe place and take a brief nap & 80 \\
Take a nap during break time at work & 80 \\
Call a friend and talk on a cell phone (with headset) & 80 \\
Carpool or take public transportation & 66 \\
Find a job closer to home & 66 \\
Purchase an electronic gadget that alerts you when your head drops & 46 \\
Stop at a friend's house close to the job and sleep & 40 \\
\hline
\end{tabular}

\section{Discussion}

The purpose of this qualitative, exploratory multiple case study was to explore the strategies nurses implemented to lessen the possibility of driving while drowsy. Although differing in approach, the predominant issue of most of the studies in the literature review involved the global hazards of drowsy driving, but few researchers have studied strategies night-shift nurses implement to lessen the possibility of driving while drowsy. Most studies focused on the quantitative use of drowsy driving countermeasures. Few studies focused on the personal driving challenges of night nurses and the strategies they use when drowsy.

The current study expanded upon studies in the literature review and focused on the personal experiences of 12 nurses from hospitals, nursing homes, or home health facilities in Central Florida and other locations via professional referrals staffing for 24-hour patient care, which presents unique challenges for night workers. In addition to fatigue and drowsiness relating to changes in circadian rhythms, the night nurse must continue to perform the same duties as day-shift nurses and commute to and from work. The night nurse also has stressors such as caring for dependent children or aging parents, continuing education or working multiple jobs. The participants reflected on the strategies they used for drowsy driving prevention, such as eating crunchy foods, drinking coffee, and listening to audio books. Only one of the 12 participants reported having discussed drowsy driving challenges and prevention strategies with managers.

This study identified the driving challenges nurses primarily in Central Florida currently face when working the night shift in hospitals, nursing homes, and home health care settings. There are similarities between previous studies that investigated increased problems with drowsy driving among nurses. Dorrian et al. (2008) reported that exhaustion relat- 
ing to working consecutive night shifts contributed to seven incidents where automobile accidents nearly occurred during a 1-month period among a sample of 41 nurses. Additionally, Ayed, Thulth, and Sayej (2015) posited that most night-shift nurses have not received education on fatigue awareness and systems they can implement to battle weariness in the work environment or when driving.

The outcomes, analyses of the research questions, and the hypotheses were discussed. Findings were compared to the literature and reviewed for practical implications, limitations, and recommendations for future study. The interview data support the assumptions that RNs and LPNs working the night shift experienced similar driving drowsy challenges. The data also supports driving distance as a significant variable in drowsy driving among the participants. Participants were more likely to fall asleep at the wheel as driving distance increased, although some participants experienced the same drowsy driving challenges on shorter distances.

\section{REFERENCES}

[1] Costa G. Introduction to Problems of shift work. Social and family Issues in shift work and non-standard working hours. 2016 Jul; 19(35): 16-26.

[2] Caruso CC, Baldwin CM, Berger A, et al. Position statement: Reducing fatigue associated with sleep deficiency and work hours in nurses. Nursing Outlook. 2017 Nov; 65(6): 766-8.

[3] Mulhall M, Sletten T, Magee M, et al. Sleepiness and Driving Incidents In Nurses Commuting To And From Work Shifts. Sleep. 2017 Apr; 40(suppl 1).

[4] Smith-Miller CA, Curro B, Shaw-Kokot J, et al. An integrative review: Fatigue among nurses in acute care settings. Journal of Nursing Administration. 2014 Sep; 44: 487-494.

[5] Trinkoff AM, Geiger-Brown J. Sleep-deprived nurses sleep and schedule challenges in nursing. American Journal of Nursing. 2017 Jan; 1(2): 123-128.

[6] Vitale SA, Varrone-Ganesh J, Vu M. Nurses working the night shift: Impact on home, family and social life. Journal of Nursing Education and Practice. 2015; 5(10): 70-78. https://doi.org/10.5430/jn ep.v5n10p70

[7] Abe T, Mollicone D, Basner M, et al. Sleepiness and safety: Where biology needs technology. Sleep and Biological Rhythms. 2014 Apr; 12(2): 74-84.

[8] Brown T. Effects of sleep deprivation and low blood alcohol on driving capacities in young people. Canadian Institute of Health Research 2014 Feb; 8(16): 17-34.

[9] Watling C, Armstrong K, Obst P, et al. Continuing to drive while sleepy: The influence of sleepiness countermeasures, motivation for driving sleepy and risk perception. Accident Analysis and Prevention. 2014 Dec; 73(1): 262-268.

[10] Dorrian J, Tolley C, Lamond N, et al. Sleep and errors in a group of Australian hospital nurses at work and during the commute. Applied Ergonomics. 2008 Sep; 39: 605-613.

\section{Conclusion}

There is a gap in the available resources regarding drowsy driving, especially concerning the value of the night nurse getting enough sleep. Once hired, night nurses usually receive little to no instruction on how to manage sleep loss. ${ }^{[2]}$ To mitigate this educational gap, the National Institute for Occupational Safety and Health created a free online training program to educate nurses and their managers about the health and safety risks associated with shift work, long work hours, and related workplace fatigue issues and relay strategies in the workplace and in the nurse's personal life to reduce these risks. ${ }^{[25]}$ Additionally, managers could add drowsy driving awareness information to online organizational communication media, staff bulletin boards, and agendas at departmental meetings. Staff members could also receive incentives for completing defensive driving training courses the organization provides.

\section{Conflicts OF InTERest Disclosure}

The authors declare that there is no conflict of interest.
[11] Scott LD, Hoffmeister N, Rogness N, et al. An interventional approach to patient and nurse safety: A fatigue counter measure feasibility study. Nurse Researcher. 2010 Jul; 59(4): 250-258.

[12] Higgins JS, Michael J, Austin R, et al. Asleep at the wheel-The road to addressing drowsy driving. Sleep. 2017 Jan; 40(2): zxs001.

[13] Han K, Trinkoff AM, Geiger-Brown J. Factors associated with workrelated fatigue and recovery in hospital nurses working 12-hour shifts. Workplace Health \& Safety. 2014 Sep; 62(10): 409-414.

[14] Anderson C, Ftouni S, Ronda JM, et al. Self-reported drowsiness and safety outcomes while driving after an extended duration work shift in trainee physicians. Sleep. $2017 \mathrm{Dec}$; 41(2).

[15] Owens JM, Dingus TA, Guo F, et al. Prevalence of drowsy-driving crashes: Estimates from a large-scale naturalistic driving study. AAA Foundation for Traffic Safety. 2018.

[16] Lee CJ, Geiger-Brown J, Beck KH. Intentions and willingness to drive while drowsy among university students: An application of an extended theory of planned behavior model. Accident Analysis \& Prevention. 2016 Aug; 93(1): 113-123.

[17] Genuardi MV, Althouse AD, Sharbaugh MS, et al. Race, ethnicity, and risk factors associated with falling asleep while driving. Sleep. 2018 Apr; 41(suppl 1): A276.

[18] Tang R, Athey A, Tang Killgore W, et al. Drowsy driving in student athletes: Impact of insomnia, sleepiness, and mood. Sleep. 2018 Apr; 41(suppl 1): A73-A73.

[19] Fallis WM, McMillan DE, Edwards MP. Napping during night-shift: Practices, preferences, and perceptions of critical care and emergency department nurses. Critical Care Nurse. 2011; 31(2): e1-11. https://doi.org/10.4037/ccn2011710

[20] Kunert K, King ML, Kolkhorst FW. Fatigue and sleep quality in nurses. Journal of Psychosocial Nursing and Mental Health Services. 2007 Aug; 45(8): 30-37. 
[21] Yin RK. Case study research and applications: Design and methods. Sage publications; 2017, $216 \mathrm{p}$.

[22] Saldaña J. Blue-collar qualitative research. Qualitative Inquiry. 2014; 20: 976-980. https://doi.org/10.1177/1077800413513739

[23] Lewis S. Qualitative inquiry and research design: Choosing among five approaches. Health Promotion Practice. 2015 Apr; 16: 473-475. https://doi.org/10.1177/1524839915580941

[24] Ayed A, Thulth AS, Sayej S. Impact of night shift and training de- velopment factors on performance of professional nurses in North West Bank governmental hospitals. Journal of Education and Practice. 2015; 6(27): 50-60.

[25] NIOSH, Caruso CC, Geiger-Brown J, et al. NIOSH training for nurses on shift work and long work hours. (DHHS (NIOSH) Publication No. 2015-115). Cincinnati, OH: US Department of Health and Human Services, Centers for Disease Control and Prevention, National Institute for Occupational Safety and Health. 2015. Available from: https://www.cdc.gov/niosh/docs/2015-115/ 